\title{
O efeito da anterioridade e da altura na identificação das vogais médias altas e médias baixas do Português Brasileiro por falantes de espanhol
}

\author{
The effect of frontness and height in the identification of open-mid vowels and \\ close-mid vowels in Brazilian Portuguese by Spanish speakers \\ Juliana Andrade Feiden \\ Ubiratã Kickhöfel Alves \\ Ingrid Finger \\ Universidade Federal do Rio Grande do Sul - Porto Alegre - Rio Grande do Sul - Brasil
}

$\diamond$

\begin{abstract}
Resumo: Falantes de espanhol como língua materna geralmente apresentam dificuldade em identificar as vogais médias altas e baixas [e], [ع], [o], [o] do Português Brasileiro (PB). O objetivo deste estudo é verificar os efeitos de anterioridade e de altura na percepção dessas vogais, através de um teste de identificação, aplicado a 16 falantes do espanhol Rioplatense, com idades entre 16 e 18 anos, utilizando-se pares mínimos do PB. Os resultados mostraram que, tanto nas vogais anteriores quanto nas posteriores, os participantes obtiveram índice mais elevado de acerto nos itens que continham vogais médias altas comparados aos itens contendo vogais médias baixas. Os resultados confirmam a dificuldade de identificação das médias do PB por argentinos, bem como evidenciam que os aprendizes em questão se encontram em um estágio de formação das novas categorias fonético-fonológicas da L2, apesar da dificuldade da delimitação dos aspectos acústico-articulatórios que caracterizam tais categorias.
\end{abstract}

Palavras-chave: Anterioridade; altura; Identificação das vogais médias altas e médias baixas; Português como L2

\begin{abstract}
Speakers of L1 Spanish have difficulty discriminating the open and close-mid vowels [e], [ع], [o], [o] in Brazilian Portuguese (BP). The goal of this paper is to verify the effects of frontness and height in the perception of these vowels. A test of vowel identification was given to 16 speakers of Argentine Spanish, aged between 16 e 18 years, using minimal pairs in BP. Results show that, in both front and back vowels, participants had higher scores in items containing close-mid vowels if compared with items containing open-mid vowels In relation to the frontness effect, participants also demonstrated more difficulty in identifying open-mid vowels than close-mid vowels. The results confirm the difficulty of Spanish speakers in identifying mid vowels of BP, as well as provide evidence that these learners are forming new L2 phonetic-phonological categories, despite the difficulty of defining aspects that characterize such acoustic-articulatory categories.
\end{abstract}

Keywords: Frontness; height; Identification of open-mid vowels and close mid-vowels; L2 Brazilian Portuguese

\section{Introdução}

Ao iniciar o processo de aquisição de uma segunda língua (L2) ${ }^{1}$, o aprendiz pode enfrentar di-

\footnotetext{
1 No presente trabalho, não é feita distinção entre os termos 'segunda língua' e 'língua estrangeira'.
}

ficuldades em relação ao conhecimento fonéticofonológico ${ }^{2}$ do novo sistema linguístico. No que diz

\footnotetext{
2 Seguindo Zimmer e Alves (2006, 2012), utilizamos, neste trabalho, o termo 'fonético-fonológico', termo esse que consegue expressar a gradiência e a continuidade entre o fone físico e o fonema (ALBANO, 2001, 2002, 2012). É pertinente ressaltar, ainda, que o Modelo Perceptual
} 
respeito à percepção dos sons da língua-alvo, ao não conseguir discriminar ou identificar as diferenças entre segmentos distintos de sua língua materna (L1) e de sua segunda língua, o aprendiz pode vir a agrupar sons pertencentes à L2 nas mesmas categorias fonológicas em que alocou anteriormente os segmentos de sua L1.

Em relação ao processo de aprendizagem do português brasileiro como língua estrangeira, ao focarmos principalmente na percepção do sistema vocálico, um fenômeno interessante que tem sido observado não somente em sala de aula, mas, também, por diversos estudos (ALLEGRO, 2010; GUIMARÃES，2011; CARVALHO e BUENO, 2013) é a dificuldade que os aprendizes hispano-falantes demonstram em adquirir a distinção entre as vogais médias-baixas [ع], [o] e médias-altas $[\mathrm{e}],[\mathrm{o}]$ do português ou, mais precisamente, em distingui-los em diferentes categorias fonéticofonológicas. $\mathrm{O}$ espanhol, incluindo todas as variantes da língua, apresenta cinco vogais orais $[i, e, a, o, u]$. Cada uma das vogais ocorre tanto em sílabas átonas como em sílabas tônicas (MARTÍNEZ-CELDRÁN et al., 2003). Por sua vez, o sistema vocálico do português brasileiro apresenta sete vogais orais tônicas, de modo a exibir as vogais médias-baixas [ $\varepsilon]$ e [0] que não ocorrem no espanhol (ALBANO, 2004).

As diferenças descritas acima implicam dificuldades tanto em termos de percepção, quanto de produção, das vogais médias do PB para falantes nativos de espanhol (cf. ALLEGRO, 2010; GUIMARÃES, 2011; CARVALHO e BUENO, 2013; MACHRY DA SILVA, no prelo). Os aprendizes demonstram dificuldades em distinguir entre as vogais médias baixas e médias altas, de modo a alegarem não perceber nenhuma diferença na pronúncia desses sons. Acreditamos que esse tipo de fenômeno não deve ser tratado meramente como uma dificuldade de pronúncia, mas como uma questão de inteligibilidade, já que, ao não perceber uma diferença de produção dos sons vocálicos, este fato pode acarretar uma falha de comunicação ou, ainda, uma dificuldade do aprendiz de se fazer entender nos diferentes contextos de comunicação em PB.

\footnotetext{
de Assimilação-L2 (Perceptual Assimilation Model-L2) (BEST e TYLER, 2007), modelo perceptual utilizado como base para o presente trabalho, se encontra em consonância, também, com tal concepção, visto que o modelo em questão sustenta, como primitivo da fonologia, o gesto articulatório (cf. BROWMAN e GOLDSTEIN, 1989, 1992).

3 Seguindo Zimmer e Alves (2006, 2012), utilizamos, neste trabalho, o termo 'fonético-fonológico', termo esse que consegue expressar a gradiência e a continuidade entre o fone físico e o fonema (ALBANO, 2001, 2002, 2012). É pertinente ressaltar, ainda, que o Modelo Perceptual de Assimilação-L2 (Perceptual Assimilation Model-L2) (BEST e TYLER, 2007), modelo perceptual utilizado como base para o presente trabalho, se encontra em consonância, também, com tal concepção, visto que o modelo em questão sustenta, como primitivo da fonologia, o gesto
} articulatório (cf. BROWMAN e GOLDSTEIN, 1989, 1992)
Com base nas considerações apresentadas acima, este artigo visa a investigar a identificação das vogais $[\mathrm{e}],[\varepsilon],[\mathrm{o}],[0]$ por alunos argentinos, falantes nativos do espanhol marplatense, aprendizes de português brasileiro como L2. Tendo-se como base o Modelo de Assimilação Perceptual-L2 (PAM-L2), proposto por Best e Tyler (2007), investigamos, a partir dos resultados de um teste de Identificação, os efeitos de altura e anterioridade na percepção das vogais da língua alvo, de modo a verificarmos se as vogais não existentes nos sistemas da L1 seriam atribuídas pelos participantes às categorias fonético-fonológicas de sua língua materna, ou se haveria a formação de novas categorias fonológicas para tais vogais.

O presente artigo está organizado da seguinte forma: na seção a seguir, será apresentada a discussão teórica referente à percepção de sons em L2, tendo-se por base as premissas do Modelo de Assimilação Perceptual - L2, proposto por Best e Tyler (2007). Na seção seguinte, serão apresentados os objetivos e as hipóteses da presente pesquisa, assim como os procedimentos metodológicos que nortearam o estudo, as características da amostra e dos estímulos utilizados nos testes. Na seção posterior, serão discutidos os principais resultados gerados pela análise estatística das respostas fornecidas pelos participantes no teste de identificação. Por fim, serão apresentadas as considerações finais, de acordo com as hipóteses levantadas pelo estudo.

\section{Referencial teórico}

\subsection{Estudos na área da percepção de sons em língua estrangeira}

Diversos estudos realizados na área da percepção de sons de um novo sistema de sons (FLEGE, 1995, 2002; KUHL e IVERSON, 1995; KUHL, 2000; BEST, 1995, BEST e TYLER, 2007) mostraram que a forma como um ouvinte percebe um som depende de sua experiência linguística. Quando falamos em experiência linguística, podemos considerar o contato prévio com algum estímulo de uma nova língua, assim como a trajetória de desenvolvimento da língua nativa ou da L1 do indivíduo. Essa experiência linguística pode, dessa forma, se tornar crucial na formação da capacidade do indivíduo em perceber detalhes e estabelecer categorias fonéticofonológicas da fala. No caso de um indivíduo que está aprendendo uma nova língua, a sua percepção poderá ser influenciada pela idade de início de aquisição dessa L2 (cf. FLEGE, 1995, 2001), o tipo de input e a exposição a esse input, o tipo e a frequência de uso da sua L1 e da sua L2, dentre outros (para discussão, ver Ortega, 2009). 
A percepção de um elemento sonoro será diferente entre um naïve learner (BEST, 1995), que consiste em um indivíduo que ouve o estímulo de uma dada língua estrangeira, porém não está necessariamente aprendendo aquela L2 e nunca teve nenhuma experiência com tal sistema linguístico, e um aprendiz e ouvinte de uma L2, que estará, durante o processo de aprendizagem da segunda língua, condicionando-se a perceber os sons ao ser exposto ao input da língua que está aprendendo (BEST e TYLER, 2007). No presente estudo, analisaremos os dados através do viés dos ouvintes aprendizes de uma L2 que, no caso desta pesquisa, são alunos de português brasileiro falantes de espanhol como L1.

Ao pensarmos em modelos que tratem da percepção de sons para nortearem a presente investigação, é importante lançarmos mão dos estudos realizados por Best (1995), através da proposta do Modelo de Assimilação Perceptual (PAM), voltado a aprendizes do tipo nä̈ve, e de Best e Tyler (2007), em que é proposto o Modelo de Assimilação Perceptual - L2 (PAM-L2), voltado a aprendizes de língua estrangeira, sendo essa proposta utilizada, no presente trabalho, como base teórica para o entendimento da percepção dos aprendizes argentinos de PB. De acordo com o PAM-L2 (BEST e TYLER, 2007), que tem por primitivo basilar o gesto articulatório (BROWMAN e GOLDSTEIN, 1989, 1992), o indivíduo, ao aprender a perceber, se torna capaz de detectar as propriedades articulatórias de caráter mais frequente, na cadeia sonora de L2 presente na fala. Para isso, o fato da experiência linguística, através da atenção, é de crucial importância para a percepção do estímulo da línguaalvo. De acordo com Best e Tyler (2007), propriedades relevantes do discurso e da linguagem não são passíveis de diferenciação somente em termos de uma diferenciação de características meramente acústico-articulatórias, mas remetem a um alto nível de caráter funcional. Através do primitivo gestual, a partir do qual tal modelo teórico se instancia, o aprendiz organiza os sons da L2 junto àquelas categorias funcionais da $\mathrm{L} 1$, ou, então, consegue formar novas categorias funcionais para os novos elementos da língua-alvo, capacidade essa que é atingida e aperfeiçoada com a experiência. Em outras palavras, os sons da L2 podem ser caracterizados como exemplares mais ou menos apropriados de uma categoria fonológica já existente na L1, ou como tokens de uma categoria nova, já da língua-alvo, o que acontece quando as diferenças funcionais entre os sons da L2 já são identificadas.

Neste sentido, observa-se no PAM-L2 a existência de um processamento de nível superior (higher level), que consiste na informação da fala que é relevante para diferenças lexicais mínimas em uma dada língua, e uma categoria de processamento de nível inferior (lowerlevel), voltada ao detalhe do tipo fine-grained, mostrando que as relações gestuais invariantes são sistemáticas e potencialmente perceptíveis aos ouvintes como percepção mais estreita, como alofones posicionais ou diferentes realizações de uma categoria fonológica entre dialetos ou línguas. Em relação a essas duas categorias estabelecidas, é possível dizer que a estrutura gestual serve como uma base de toda a organização fonológica, sendo a fonética e a fonologia partes indissociáveis de um mesmo sistema. Partindo da exemplificação didática de que o aprendiz estará sendo exposto a pares contrastivos de sons da L2, e de que os novos sons podem ser 'assimilados' (ou seja, atraídos e agrupados) a categorias funcionais já existentes na L1, o modelo apresenta quatro possibilidade de categorizações e contrates mínimos dos pares de sons da língua-alvo, que os aprendizes percebem como elementos da fala:

1. somente uma categoria fonológica da L2 é percebida como equivalente (assimilada perceptualmente) a uma determinada categoria fonológica da L1.

Neste caso, havendo somente contraste entre duas categorias fonológicas da L2, o indivíduo percebe uma dessas categorias como sendo equivalente a uma categoria fonológica da L1. A outra categoria não assimilada pode ser percebida como um bom exemplar de uma outra categoria da L1, ou pode ser não categorizada.

2. Ambas as categorias fonológicas são percebidas como equivalentes a uma mesma categoria fonológica da L1, porém uma é percebida como sendo mais desviante do que a outra.

Os aprendizes seriam capazes de discriminar esses segmentos da L2, porém não tão bem como se os discriminassem em duas categorias distintas. Assim, sons pertencentes a categorias fonológicas distintas da L2 são percebidos como pertencentes à mesma categoria fonológica da L1, porém uma das categorias é considerada mais desviante. Neste caso, espera-se que o indivíduo seja capaz de discriminar sem muita dificuldade os dois fones da L2, mas não tão bem como na discriminação de elementos fônicos da L2 que fossem classificados em categorias fonológicas diferentes daquela da L1.

\section{Ambas as categorias fonológicas são percebidas como equivalentes a uma mesma categoria fonológica da L1, mas são igualmente exemplares bons ou desviantes de uma mesma categoria.}

Neste caso, ocorre uma assimilação única de um contraste da L2. O aprendiz, sob essa hipótese, apresentará dificuldade em discriminar os dois fones da L2, que serão ambos assimilados a uma única categoria da L1, e palavras que contenham esses fones como contrastes 
mínimos serão consideradas como homófonas. Para que o indivíduo venha a separar essas duas categorias fonológicas da L2, de modo que pertençam a duas categorias distintas, o aprendiz precisará, primeiramente, aprender perceptualmente uma nova categoria fonética para pelo menos um dos fones da L2 que estão em conflito. Um fator crucial para a possibilidade de se aprender a perceber e a criar uma nova categoria funcional seria $o$ domínio de alguns sons em relação a outros e a importância de detectar diferenças entre palavras da L2 que possuem um contraste mínimo, ou seja, se a palavra-alvo for de alta frequência de uso, ou se precisa ser discriminada para permitir a compreensão correta, a pressão referente à inteligibilidade, para o entendimento de um segmento, pode encorajar o falante da L2 a aprender essa distinção.

4. Não há assimilação entre as categorias fonológicas da L1 e da L2.

Se o indivíduo não encontrar uma categoria da sua L1 que seja capaz de alocar os dois fones da L2, não ocorrerá a assimilação fonológica da L2 para a L1. O aprendiz, neste caso, perceberá que os dois fones da L2 apresentam similaridades em relação a diferentes aspectos dos fones da L1. Dessa forma, esses fones serão distantes um do outro dentro do espaço fonológico da L1, sendo criadas novas e distintas categorias fonológicas para cada um deles.

Este trabalho, portanto, tem a intenção de verificar se os pares de sons vocálicos [e] $v s$. [ $[\varepsilon] \mathrm{e}[\mathrm{o}] v s$. [o] são assimilados apenas a uma categoria da L1, correspondente à daquela vogal pertencente ao sistema da língua materna, ou se os aprendizes já se mostram capazes de organizar os segmentos da L2 em duas categorias distintas no sistema da sua interlíngua. Verificada a possibilidade de assimilação dos sons da L2, o trabalho tem a intenção de discutir, também, se as vogais médias altas e médias baixas, quando assimiladas, são tidas como representantes igualmente bons da categoria fonético-fonológica a que foram atribuídas. Ao descrevermos e analisarmos os dados, as hipóteses supracitadas, levantadas por Best e Tyler (2007), serão retomadas na discussão dos resultados.

\section{0 estudo}

\subsection{Objetivos e hipóteses}

O presente estudo teve como objetivo geral investigar os índices de identificação das vogais médias do PB por um grupo de adolescentes argentinos, falantes de espanhol como língua materna. Mais especificamente, verificamos os efeitos de anterioridade e de altura na percepção das vogais médias do $\mathrm{PB}$ em uma tarefa de identificação vocálica. Com base em resultados de estudos anteriores (ALLEGRO, 2010; CARVALHO e BUENO, 2013), tínhamos como hipótese obter efeitos significativos tanto de altura como de anterioridade nos escores obtidos pelos participantes na tarefa. Em outras palavras, esperávamos um índice maior de acertos nas vogais altas [e] e [o] em comparação com as baixas $[\varepsilon]$ e [o], bem como nas anteriores $[\mathrm{e}] \mathrm{e}[\varepsilon]$ em comparação com as posteriores [o] e [o].

\subsection{Participantes}

Os dados para a realização da pesquisa foram coletados em um grupo de 16 adolescentes (de 16 e 18 anos, média $=17,4$ anos) falantes de espanhol argentino como língua materna, estudantes do ensino médio, que cursavam uma disciplina de língua portuguesa em uma escola na Argentina, e que vieram para Porto Alegre para realizar um intercâmbio de 3 semanas no Colégio de Aplicação da Universidade Federal do Rio Grande do Sul. Os alunos participantes cursavam a disciplina de português há, pelo menos, 2 anos (média $=2,87$ anos), sendo que não foi possível aplicar um teste de proficiência do português brasileiro a fim de se verificar qual o nível de proficiência dos participantes (dificuldade essa discutida em Quintanilha-Azevedo, 2010). Do total de 16 participantes, 6 eram do sexo masculino e 10 do sexo feminino. Todos os sujeitos participaram de forma voluntária da pesquisa e assinaram um Termo de Consentimento Livre e Esclarecido, cuja cópia foi fornecida aos participantes.

\subsection{Instrumento e procedimentos de coleta de dados}

Para que fosse possível atingir os objetivos propostos no estudo, um teste de identificação de vogais foi elaborado e aplicado através da utilização do software Praat - versão 5.3.32 (BOERSMA e WEENINK, 2012). Para a criação do teste, foram selecionados pares mínimos do PB, através de palavras formadas por 4 fonemas e duas sílabas, sendo a primeira a sílaba tônica. Na tabela abaixo, são apresentados alguns exemplos de pares mínimos utilizados no teste de identificação:

Quadro 1 - Exemplos de pares mínimos

\begin{tabular}{|l|l|}
\hline Pares mínimos: [e] e [ $\varepsilon]$ & Pares mínimos: [o] e [o] \\
\hline Gelo (Substantivo) - Gelo (Verbo) & Boto (Substantivo) - Boto (Verbo) \\
\hline Pelo (Substantivo) - Pelo (Verbo) & Jogo (Substantivo) - Jogo (Verbo) \\
\hline Peso (Substantivo) - Peso (Verbo) & Poço (Substantivo) - Posso (Verbo) \\
\hline Selo (Substantivo) - Selo (Verbo) & Soco (Substantivo) - Soco (Verbo) \\
\hline
\end{tabular}


A gravação dos estímulos que foram utilizados no teste foi feita com 4 voluntários, sendo duas mulheres e dois homens, com idades entre 25 e 38 anos. Todos eram falantes nativos do PB, nascidos em Porto Alegre e com nível de escolaridade universitária. As gravações ocorreram em um estúdio de gravação com isolamento acústico na cidade de Porto Alegre. Depois da gravação, cada estímulo foi editado no programa Praat, para que todos tivessem a mesma duração no teste (entre $1,4 / 1,5 \mathrm{~s}$ ).

O teste de identificação foi composto por 64 palavras, repetidas uma vez de forma aleatória, totalizando 128 estímulos. Nesse teste, solicitou-se aos participantes que eles escutassem uma das palavras apresentadas e identificassem qual era a primeira vogal da primeira sílaba dessas palavras. Para cada uma das quatro vogais testadas ([e], [ع], [o], e [o]), foram utilizados 16 estímulos.

No momento da realização do teste de identificação, foi explicado aos participantes que os mesmos ouviriam uma palavra do $\mathrm{PB}$ e que deveriam identificar a primeira vogal desta palavra, escolhendo, dentre as sete vogais do português brasileiro, a opção percebida. Para que fosse possível para os participantes identificar os sons [o] e [ $\varepsilon]$, através das letras do alfabeto latino, foram dadas como exemplo palavras que apresentassem as vogais acentuadas. No que segue, é apresentada a tela do software Praat (Figura 1), mostrando o enunciado da tarefa, assim como as opções que os participantes tinham ao escolherem a melhor resposta depois de terem escutado os estímulos.

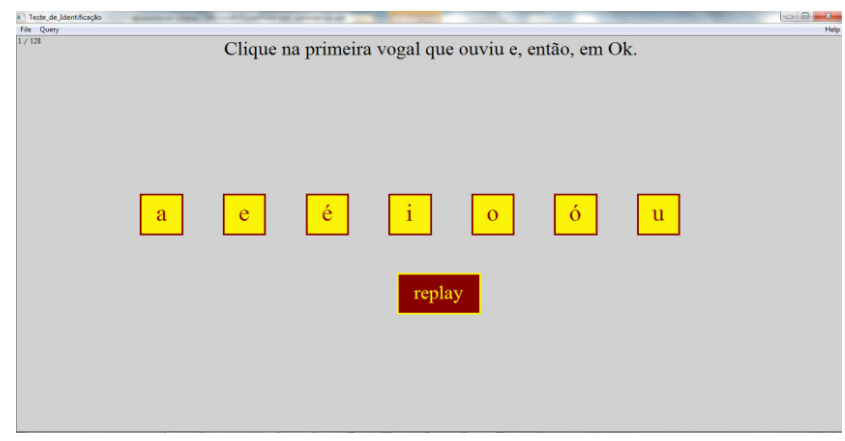

Figura 1 - Tela do software Praat - Teste de Identificação

\section{Análise e discussão dos dados}

$\mathrm{Na}$ análise de dados, realizada com o software estatístico SPSS (Versão 19), adotou-se o valor de $p=0,05$ como sendo significativo. A Tabela 1 apresenta os resultados gerais dos participantes no teste de identificação de vogais.
Tabela 1 - Dados gerais do teste de identificação (de um total de 32 itens-alvo com cada vogal - Total: 128 itens alvo no teste)

\begin{tabular}{llcc}
\hline Anterioridade & \multicolumn{1}{c}{ Altura } & Média (\% acertos) & Desvio padrão \\
\hline \multirow{2}{*}{ Anterior } & Média alta $(\mathrm{e})$ & $18,44(57,6 \%)$ & 7,13 \\
& Média baixa $(\varepsilon)$ & $12,25(38,3 \%)$ & 7,5 \\
\multirow{2}{*}{ Posterior } & Média alta $(0)$ & $20,44(63,9 \%)$ & 5,6 \\
\multirow{2}{*}{ Total } & Média baixa $(0)$ & $8,38(26,2 \%)$ & 5,15 \\
& & $59,50(46,5 \%)$ & 6,09 \\
\hline
\end{tabular}

Como podemos observar na tabela acima, tanto no caso das vogais anteriores quanto posteriores, os participantes obtiveram índices mais elevados de acerto nos itens do teste que continham vogais médias altas (mais semelhantes àquelas de seu sistema de L1) em comparação aos itens contendo vogais médias baixas. Uma ANOVA de Medidas Repetidas $2 \times 2$ considerando anterioridade e altura como variáveis independentes, com duas condições cada (anterior/posterior, alta/baixa, respectivamente), gerou uma interação significativa entre anterioridade e altura $(F(1,15)=4,552, p=0,050)$ e um efeito principal de anterioridade $(F(1,15)=11,401, p=0,004)$. A fim de verificar a origem da significância estatística obtida na comparação entre os efeitos de anterioridade e de altura, realizamos uma série de testes- $t$, cujos resultados serão relatados a seguir.

A comparação entre os escores obtidos pelos aprendizes nos itens do teste que incluíam vogais anteriores médias-altas ([e]) e médias-baixas $([\varepsilon])$ revelou significância estatística $(t(15)=1,758, p=0,099)$, indicando um efeito da altura da vogal na identificação dos sons vocálicos contidos nas palavras do teste pelos participantes. Pode-se afirmar que os aprendizes demonstraram mais dificuldade de identificar vogais médias baixas do que médias altas no teste, ainda que, mesmo nos itens de estímulo que apresentam vogal média alta, o índice de acerto tenha sido menor do que $60 \%$.

Da mesma forma, no caso dos itens que continham vogais posteriores, a comparação entre os escores obtidos pelos participantes na identificação da vogal média alta [o] e da média baixa [o] indicou significância estatística $(t(15)=4,923, p<0,0001)$, o que sugere um efeito da altura da vogal na percepção das vogais [o] e [o] nas palavras do teste. Nesse caso, as vogais baixas apresentaram um desafio maior do que as altas, sendo que o índice de acurácia foi ainda menor do que no caso das anteriores.

A comparação entre os escores obtidos nos itens do teste que continham a vogal média alta anterior [e] e a média alta posterior [o] não revelou significância estatística. Entretanto, foi encontrado um efeito significativo de anterioridade na comparação entre as vogais médias baixas $[\varepsilon]$ e $[0](t(15)=-2,225, p=0,042)$. 
Os resultados aqui apresentados evidenciam a dificuldade do aprendiz de identificar as vogais médias do PB. Não surpreendentemente, essa dificuldade mostrase maior no que diz respeito à percepção das médias baixas, uma vez que a língua materna dos aprendizes não apresenta vogais com essa altura. De fato, os índices de acuidade referentes às médias baixas, inferiores a 50 por cento, indicam que os aprendizes, frente aos novos sons da L2, tendem a organizar tais vogais sob uma categoria fonético-fonológica pré-existente, como aquela da $\mathrm{L}^{4}$. Ressalta-se, outrossim, a maior dificuldade de identificação, por parte dos participantes do estudo, frente a vogais posteriores, fato esse também já verificado em outros estudos que envolvem tanto percepção (ALLEGRO, 2010) quanto produção (CARVALHO e BUENO, 2013), de acordo com os quais os índices de acuidade são sempre inferiores para a distinção entre [o] e [o] do que para o contraste entre $[e]$ e $[\varepsilon]$. Como um possível fator responsável por tal diferença, mostrase interessante mencionar o arredondamento das vogais posteriores, que exerce efeitos não somente sobre F3, mas também sobre os valores de F2 e F1 (KENT e READ, 1992).

Considerando-se os postulados de Best e Tyler (2007), poderíamos pensar, em princípio, que tanto as vogais médias altas quanto as médias baixas são organizadas dentro de uma mesma categoria, referente a vogais médias-altas, visto que são essas as que ocorrem efetivamente na L1 dos participantes. Entretanto, antes de uma conclusão pontual nesse sentido, é interessante mencionar que, surpreendentemente, os índices de identificação referentes às vogais médias altas se mostraram inferiores ao que era previamente esperado, a partir dos postulados do PAM-L2. De fato, conforme pode ser visto na Tabela 1, ainda que as vogais médias altas sejam mais facilmente identificadas do que as médias baixas, os índices de acuidade referentes às vogais [e] e [o] são, mesmo assim, inferiores a $70 \%$. Tais índices servem como evidência contra uma primeira hipótese de que, pelo fato de que a L1 dos aprendizes possui médias-altas, os índices de acuidade referentes à identificação de tais vogais na L2 seriam praticamente categóricos. Como uma possível explicação para tal fato, podem-se considerar os valores de F1 das vogais médias altas no Português Brasileiro e no espanhol. Conforme a caracterização das vogais do Português Brasileiro proposta por Behlau et al. (1998), a média alta anterior [e] apresentaria o valor médio de $563 \mathrm{~Hz}$, ao passo que a posterior [o] seria caracterizada por um valor médio de $558 \mathrm{~Hz}$. Esses valores mostram-se distintos daqueles propostos para o espanhol, pois, conforme dados da Real Academia Espanhola (2011), a vogal [e] apresenta um F1 médio de $465 \mathrm{~Hz}$, ao passo que [o] apresenta valores próximos de $455 \mathrm{~Hz}$ (sendo caracterizados, portanto, como mais altas do que aquelas do PB, considerando-se os valores aqui apontados). Com referência às vogais da variedade rioplatense, Blank (2013) prevê, para falantes de Montevideo, as médias de 472 para [e] e 500 para [o], e García-Jurado e Arenas (2005) prevêem valores com início em $400 \mathrm{~Hz}$, o que corresponde a vogais ainda mais altas do que aquelas previstas pela Real Academia Española.

Considerados esses valores ${ }^{5}$, e a consequente possibilidade de que as médias altas do espanhol sejam, efetivamente, mais altas do que aquelas do português, as vogais [e] e [o] do português, por apresentarem uma altura mais baixa do que aquela da L1 dos participantes, podem vir a impor um certo grau de dificuldade em termos perceptuais. Em outras palavras, tendo-se por base uma concepção de primitivo articulatório, assim como defendem Best e Tyler (2007) no PAM-L2, caberá aos aprendizes, participantes deste estudo, a tarefa de determinar os valores de temporalidade gestual que se mostram como limiares, ou fronteiriços, entre as categorias fonético-fonológicas que caracterizam a oposição entre médias baixas e médias altas da língua alvo. Nesse sentido, os próprios estímulos que contêm médias altas precisam ser "reagrupados" em uma categoria correspondente, pelo fato de que, em função das diferenças em termos de altura entre o que, em princípio, seriam as mesmas vogais nos dois sistemas, tais vogais não necessariamente vêm a ser diretamente enquadradas sob aquele rótulo da $\mathrm{L} 1$.

Visto o fato de que não somente deve ser criada uma categoria fonético-fonológica para as vogais

\footnotetext{
4 Este resultado pode ser corroborado pelas considerações feitas por Tomás (2004), bem como pelo manual de Fonética e Fonologia da Real Academia Espanhola (RAE-2011), segundo os quais, em alguns contextos, as vogais médias altas do espanhol são produzidas de forma mais aberta, de modo que tais produções mais baixas venham a constituir variantes alofônicas das vogais [e] e [o]. Considerado tal fato, verifica-se que a categoria das vogais médias altas do sistema de L1 dos aprendizes deve abarcar, também, tais produções com valores de F1 mais altos. Isso pode implicar uma dificuldade a mais, para o aprendiz hispanofalante, na separação das duas categorias de vogais, uma vez que essas coarticulações mais abertas precisam ser, também, agrupadas na categoria de médias-altas existentes na L1, visto que o espanhol apresenta apenas uma categoria funcional de altura referente às vogais médias.

5 É preciso reconhecer que existe não somente uma diferença de altura, mas, também, de anterioridade, entre vogais médias baixas e médias altas. Considerando-se a afirmação de Alves et al. (2011) e de Alves e Zimmer (2012) de que a percepção dos sons de uma L2 é o resultado de múltiplas pistas acústicas que agem em conjunto, de modo que a exclusão de uma pista, mesmo que de caráter minoritário para a perceptibilidade, pode exercer efeitos consideráveis na descriminação e na identificação dos sons da L2, julga-se que tal fato não pode ser desconsiderado. Entretanto, uma vez que, no caso da oposição entre médias-altas e médias-baixas, é a diferença nos valores de F1 entre os pares de vogais que se mostra mais acentuada, a discussão dos dados deste estudo, ainda que considerem tal fato, será centrada na diferença primordial de altura. Estudos futuros, que demonstrem o possível papel de F2 para a discriminação e a identificação de diferenças de altura entre as vogais da L2, mostram-se, portanto, necessários.
} 
médias-baixas, mas, também, que novos limiares devem ser redefinidos para a categoria das médias altas, o resultado é a tendência à instabilidade, demonstrada, a partir dos dados da Tabela 1, pelos índices encontrados tanto em médias altas quanto baixas. Uma vez que a categoria da L1 deve ser "alargada" para poder abarcar, também, as médias altas do novo sistema que está sendo adquirido (que são um pouco mais baixas), o desafio do aprendiz é determinar, conforme já dissemos, até que ponto tal permissibilidade se faz correta, de modo que alturas mais baixas, dentre as vogais médias, não sejam, também, caracterizadas como médias altas. Trata-se, na verdade, de um jogo de forças entre permissibilidade e limitação, frente à necessidade de que se estabeleçam limites gestuais para a correta formação das duas categorias.

Tomando-se as considerações acima feitas à luz dos postulados de Best e Tyler (2007), pode-se considerar que realmente há, efetivamente, um determinado grau de assimilação à categoria da L1. De fato, se, por um lado, há o que poderia ser considerado uma surpreendente dificuldade de encaixar as médias-altas da L2 na categoria da L1, por outro lado, o fato de que os aprendizes necessitam "expandir" os limites da sua categoria fonológica das médias altas, permitindo, portanto, vogais com valores de F1 mais altos até um determinado limiar, possibilita que vogais média-baixas, com valores de F1 ainda maiores, possam vir a ser incorretamete agrupadas, também nessa categoria. Por outro lado, os dados permitem considerar que, pelo menos variavelmente e em menor proporção, já há a formação de uma nova categoria, referente às vogais médias baixas, ainda que os limites acústico-articulatórios dessa categoria não estejam tampouco claros.

Uma vez que os dados sugerem haver, pelo menos insipientemente, a formação de uma nova categoria funcional da L2 para as médias baixas, categoria essa que, de certa forma, está por ora abarcando não somente um pequeno número de tokens $[\varepsilon]$ e [o] do $\mathrm{PB}$, mas, inclusive, alguns exemplares de médias-altas, a verificação do grau de adequação (category goodness) dos diferentes tipos de exemplares (médias altas ou baixas), agrupados em cada categoria, se faz necessária. Em outras palavras, resta saber se, ao categorizar vogais como média-altas, o aprendiz considerará como mais adequados os tokens de $[\mathrm{e}]$ e $[o]$ do que aqueles de $[\varepsilon]$ e [o] (bem como o oposto, no caso das médias baixas). Para tal verificação, realizamos uma análise dos erros cometidos pelos aprendizes no teste de identificação. A Tabela 2, abaixo, apresenta não somente os graus de acerto, mas, também, os índices de identificação incorreta do som. Consideramos como "identificação incorreta" ou "erro" o número de vezes em que os aprendizes perceberam a vogal média anterior alta $[\mathrm{e}]$ quando o item-alvo continha a anterior baixa $[\varepsilon]$, ou vice-versa. Em outras palavras, por erro se entende uma vogal média com a mesma anterioridade, porém com um grau de altura diferente do apresentado no estímulo. A partir da análise de erros apresentada no que segue, poderemos discutir mais claramente o nível de "adequação" de cada altura de vogal frente à categoria em que cada uma delas foi encaixada.

A fim de analisarmos estatisticamente esses resultados, realizamos uma ANOVA de Medidas Repetidas $2 \times 2$ com anterioridade e altura como variáveis independentes, que revelou interação marginal entre altura e anterioridade $(F(1,15)=3,150, p=0,096)$ e efeito principal de anterioridade $(F(1,15)=9,194, p=0,008)$. Testes- $t$ comparando os resultados de cada som de vogal com vistas a verificar preferência revelaram que no caso das vogais médias anteriores, tanto alta (e) quanto baixa $(\varepsilon)$, a comparação entre a percepção correta e incorreta da vogal não diferiu de forma significativa. Já no caso das vogais médias posteriores, houve diferença marginal entre a percepção correta $(M=20,44)$ e incorreta $(M=22,19)$ da vogal média alta posterior (o) $(t(15)=-1,894, p=0,078)$. Além disso, a análise também revelou diferença significativa $(t(15)=-2,328, p=0,034)$ entre os índices de percepção correta $(M=8,38)$ e incorreta $(M=11,13)$ da vogal média baixa posterior (o) no teste de identificação.

Os testes estatísticos realizados sugerem um comportamento diferenciado para as vogais anteriores e posteriores. No que diz respeito às anteriores [e] e [ع], verifica-se que os índices de identificação de [e] como $[\varepsilon]$, bem como de $[\varepsilon]$ como $[\varepsilon]$, são praticamente iguais, não implicando diferenças significativas entre graus de "acerto" ou "erro". Ao se tentar transpor tal resultado para a noção do quão representativo cada

Tabela 2 - Análise de erros cometidos no teste de identificação (de um total de 32 itens-alvo com cada vogal - Total: 128 itens-alvo no teste)

\begin{tabular}{lcccc}
\hline \multicolumn{1}{c}{ Resposta fornecida } & Média de acertos (DP) & Percentual de acertos & Média de erros (DP) & Percentual de erros \\
\hline Média alta anterior (e) & $18,44(7,13)$ & $57,6 \%$ & $19,44(7,42)$ & $60,8 \%$ \\
Média baixa anterior $(\varepsilon)$ & $12,25(7,5)$ & $38,3 \%$ & $12,97(7,07)$ & $40,5 \%$ \\
Média alta posterior (o) & $20,44(5,6)$ & $63,9 \%$ & $22,19(4,95)$ & $69,3 \%$ \\
Média baixa posterior (o) & $8,38(5,15)$ & $26,2 \%$ & $11,13(7,1)$ & $34,8 \%$ \\
\hline
\end{tabular}


uma dessas duas alturas de vogal é para a categorização nas categorias fonético-fonológicas de média-baixa e média-alta (category goodness), pode-se sugerir que ambos os padrões de altura apresentam o mesmo grau de representatividade, tanto para a categoria das vogais médias-altas quanto para a categoria das médias-baixas. Em outras palavras, os índices de identificação das duas vogais se mostram muito próximos, o que leva à sugestão de que o aprendiz ainda não consegue separar os limiares gestuais que permitem a categorização correta. Nesse sentido, sugere-se que as duas alturas de vogais, no que diz respeito às anteriores $[\mathrm{e}] \mathrm{e}[\varepsilon]$, são igualmente boas ou ruins, tanto para a categorização em média alta quanto em média baixa.

Já no que diz respeito às posteriores [o] e [o], a diferença significativa encontrada entre os índices de identificação, como [o], a partir de estímulos tanto com médias altas quanto com médias baixas advém, sobretudo, da superioridade da identificação incorreta da média alta. Em outras palavras, parece que, no caso dos aprendizes pesquisados, o limite de altura mínima para a categorização da vogal como média alta ainda se encontra muito alto, sendo necessário, portanto, que tais participantes aprendam a expandir tal categoria, de modo a incluir, também, vogais com valores mais altos de F1 (ou seja, com menor altura).

Em suma, do quadro que aqui se verifica, fica claro o fato de que os participantes se encontram em um estágio de formação de categorias da L2. Ainda que os aprendizes já não mais simplesmente façam uso da categoria da L1 puramente (uma vez que parece já haver o início da formação da categoria das médias baixas, além do fato de que a própria categoria de médias altas precisou, e ainda precisa, sofrer reformulações no que diz respeito aos limiares gestuais referentes à altura dos segmentos vocálicos pertencentes a esta categoria), as novas categorias fonético-fonológicas, por estarem ainda em formação, se caracterizam por uma alta variabilidade. Os aprendizes parecem estar, ainda, "testando" implicitamente os limites de altura que diferenciam uma de outra vogal, sendo que a posterioridade da vogal parece implicar, também, um fator que torna esta tarefa ainda mais difícil, uma vez que menores índices de acuidade foram encontrados para [o] e [o].

\section{Considerações finais}

Com base em estudos anteriores, nossa hipótese previa efeitos significativos tanto de altura como de anterioridade nos escores obtidos pelos participantes na tarefa de identificação de vogais. Os resultados obtidos na análise dos dados confirmam essa previsão, dado que, tanto nas vogais anteriores quanto nas posteriores, os participantes obtiveram índice mais elevado de acerto nos itens que continham vogais médias altas comparados aos itens contendo vogais médias baixas, ainda que os índices de acuidade referentes a essas vogais sejam mais baixos do que o esperado. No que diz respeito aos efeitos referentes à anterioridade, os participantes demonstraram mais dificuldade para identificar vogais médias baixas do que médias altas no teste. Os resultados confirmam a dificuldade de identificação das médias do PB por argentinos, bem como evidenciam que os aprendizes em questão se encontram em um estágio de formação das novas categorias fonético-fonológicas da L2, apesar da dificuldade da delimitação dos aspectos acústicoarticulatórios que caracterizam tais categorias.

Algumas reflexões referentes a limitações do estudo merecem destaque. Em primeiro lugar, acreditamos que seria interessante analisar acusticamente as vogais que serviram de estímulo no teste de percepção, precisando os valores de F1 e F2, com vistas a verificar os efetivos valores das frequências formânticas que foram identificadas. Uma verificação mais apurada dos efetivos valores de formantes se justifica, sobretudo, devido à possibilidade de variação desses valores. Dito isso, salientamos que, embora os valores retratados pela literatura possam não ser aqueles que estão nos estímulos, a reflexão teórica aqui proposta de qualquer modo deixa claro que a inclusão na categoria da própria L1 implica, também, uma tarefa para o aprendiz, porque, em termos de limiares articulatórios, as vogais das duas línguas podem mostrar-se bastante diferentes.

Com base na análise dos dados, de acordo com os objetivos deste trabalho, verificamos que há uma necessidade de maior reflexão acerca de tarefas metodológicas que permitem verificar a category goodness de um determinado som, pois somente através do teste de identificação não se consegue obter um quadro claro sobre a possibilidade de verificar como dois diferentes sons da L2 são classificados de acordo com uma categoria fonológica da L1 já estabelecida. Cabe mencionar que na apresentação do modelo realizada por Best e Tyler (2007), ainda que a noção de grau de adequação dos estímulos se mostre um dos principais aspectos para se verificar a formação de categorias funcionais, pouco é discutido sobre os tipos de testes e medição que permitem verificar a category goodness entre os pares de sons. Acreditamos que a análise de erros tenha representado uma tentativa válida de verificação de possíveis efeitos de category goodness, e reconhecemos que tarefas como de julgamento do estímulo ouvido após a sua identificação, através de uma Escala de Likert, em que o aprendiz possa dizer o quão "apropriado" aquele exemplar é do falar nativo, possam ser, em conjunção com a análise acústica dos estímulos ouvidos, possíveis soluções metodológicas 
para a discussão sobre category goodness que devem ser exploradas em estudos futuros.

Outro aspecto que merece destaque diz respeito aos estímulos utilizados no teste de identificação, dado que pode ter havido efeitos de classe de palavras (substantivos vs. verbos), bem como decorrente efeito de frequência de item em decorrência desse fato (verbos conjugados ocorrem menos frequentemente que substantivos). Sugerimos que, em estudos futuros, sejam utilizados itens contendo não-palavras, a fim de isolar o fator frequência de ocorrência na língua.

Pode-se finalizar dizendo que o presente trabalho contribuiu não somente empiricamente, ao descrever uma das mais importantes dificuldades a serem vencidas pelos hispanofalantes aprendizes de PB, mas, também, por sugerir que a organização dos sons da L2 em categorias implica que, até mesmo para a categorização daqueles estímulos mais semelhantes aos do sistema de L1, haja a necessidade de formação e/ou redefinição dos limiares de temporalidade gestual. Tal processo de formação de categorias sofre transformações ao longo da experiência do aprendiz com a LE, de modo a se caracterizar, portanto, como dinâmico por excelência.

\section{Referências}

ALBANO, Eleonora Cavalcante. O gesto e suas bordas: esboço da fonologia acústico-articulatória do Português Brasileiro. Campinas: Mercado de Letras, FAPESP, 2001.

ALBANO, Eleonora Cavalcante. A pulsação sob a letra: pela quebra de um silêncio histórico no estudo de som de fala. Cadernos de Estudos Linguísticos, v. 1, n. 42, p. 7-20, 2002.

ALBANO, Eleonora Cavalcante. Perspectivas recentes no estudo da aquisição e do desenvolvimento fonológico. Letras de Hoje, Porto Alegre, v. 39, n. 3, p. 75-77, 2004.

ALBANO, Eleonora Cavalcante. Uma introdução à dinâmica em fonologia, com foco nos trabalhos desta coletânea. Revista da Abralin, n. esp. 2, p. 1-30, 2012.

ALLEGRO, Fernanda. A percepção das vogais do português por hispanofalantes: um estudo envolvendo paulistanos e rioplatenses. Revista Intercâmbio, São Paulo, v. 22, p. 56-71, 2010.

ALVES, Ubiratã Kickhofel.; SCHARTZHAUPT, Bruno Morais.; BARATZ, Ana Hemmons. Percepção e produção dos padrões de VOT do inglês (L2) por aprendizes brasileiros. In: FERREIRA-GONÇALVES, Giovana; BRUM-DE-PAULA, Miriam Rose; KESKE-SOARES, Márcia (Org.). Estudos em Aquisição Fonológica. Pelotas: Editora da UFPel, 2011. v. 4. p. 179-190.

ALVES, Ubiratã Kickhofel; ZIMMER, Márcia Cristina. The dynamics of perception and production of VOT patterns in English by Brazilian learners. In: MELLO, Heliana; PETTORINO, Massimo; RASO, Tommaso (Ed.). Proceedings of the VII th GSCP International Conference: Speech and Corpora. Firenze, Itália: Firenze University Press, 2012. p. 223-227.
BEHLAU, Mara Suzana; PONTES, Paulo Augusto de Lima; TOSI, Oscar; GANANÇA, Maurício Malavasi. Análise espectrográfica de formantes das vogais do português brasileiro falado em São Paulo. In: $A C T A A W H O$, v. 7, p. 67-73, 1988,

BEST, Catherine. T. A direct realist view of cross-language speech perception. In: STRANGE, Winifred (Ed.). Speech perception and linguistic experience: issues in cross-language research. Timonium, MD: York Press, 1995. p. 171-204.

BEST, Catherine. T.; McROBERTS, Gerald W.; GOODELL, Elizabeth. American listeners' perception of nonnative consonant contrasts varying in perceptual assimilation to English phonology. Journal of the Acoustical Society of America, p. 775-794, 2001.

BLANK, Cíntia Avila. A influência grafo-fônico-fonológica na produção oral e no processamento de priming em multilingues: uma perspective dinâmica. 2013. 225fls. Tese (Doutorado em Letras) - Universidade Católica de Pelotas, Pelotas, 2013.

BOERSMA, Paul; WEENINK, David. Praat - Doing Phonetics by Computer - Version 5.3.32. 2012. Disponível em: <www. praat.org>. Acesso em: 17 out. 2012.

BROWMAN, Catherine; GOLDSTEIN, Louis. Articulatory gestures as phonological units. Phonology, v. 6, p. 201-251, 1989.

BOERSMA, Paul; WEENINK, David. Articulatory phonology: an overview. Phonetica, v. 49, p. 155-180, 1992.

CARVALHO, Márcio Palacios; BUENO, Elza Sabino da Silva. Neutralização do timbre aberto nas vogais médias no português falado como L2 em escolas públicas de fronteira. Interletras, Mato Grosso do Sul, v. 3, n. 17, p. 1-18, 2013.

FLEGE, James Emil. Second language speech learning: Theory, findings and problems. In: STRANGE, Winifred (Ed.). Speech perception and linguistic experience: Theoretical and methodological issues. Timonium, MD: York Press, 1995. p. 233-277.

FLEGE, James Emil. Interactions between the native and second-language phonetic systems. In: BURMEISTER, Petra; PIRSKE, Thorsten; RHODE, Andreas (Ed.). An integrated view of language development: papers in honor of Henning Wode. Trier: Wissenschaftliger Verlag, 2002. p. 217-243.

GARCÍA JURADO, Maria Amalia; ARENAS, M. La fonética del español. Análisis e investigación de los sonidos del habla. Buenos Aires: Quórum/Universidad del Museo Social Argentino, 2005.

GUIMARÃES, Flávia Isabel da Silva. Aquisição do português como L2 por falantes de espanhol: uma experiência com o modelo de ontogenia. 2011. 134fls. Dissertação (Mestrado em Filologia e Língua Portuguesa) - Universidade de São Paulo, 2011.

KENT, Raymond D.; READ, Charles. The acoustic analysis of speech. Los Angeles, CA: Singular/Thomson Learning, 2002. v. 2.

KUHL, Patricia; IVERSON, Paul. Linguistic experience and the 'language magnet effect'. In: STRANGE, Winifred (Ed.). Speech Perception and Linguistic Experience: Issues in CrossLanguage Research. Baltimore: York Press, 1995. p. 121-154.

KUHL, Patricia. A new view of language acquisition. Proceedings of the National Academy of Science, v. 97, p. 11850-11857, 2000. 
LADO, Robert. Linguistics across cultures. Ann Arbor: University of Michigan Press, 1957.

MACHRY, Susiele da Silva. Percepção e produção das vogais médias do português (L2) por falantes nativos do Espanhol. Tese (Doutorado em Letras) - Pontifícia Universidade Católica do Rio Grande do Sul. (no prelo)

MARTÍNEZ-CELDRÁN, Eugenio; FERNÁNDEZ-PLANAS, Ana $\mathrm{M}^{\mathrm{a}}$; CARRERA-SABATÉ, Josefina. Castillan Spanish. Journal of the International Phonetic Association, v. 33. n. 2. p. 255-259, 2003.

ORTEGA, Lourdes. Understanding Second Language Acquisition. London: Hodder Arnold, 2009.

QUINTANILHA-AZEVEDO, Roberta. A epêntese no Português Brasileiro (L2), em segmentos plosivos em codas mediais, por falantes nativos do Espanhol Colombiano (L1): uma análise via Teoria da Otimidade Estocástica e Gramática Harmônica. 2011. 180fls. Dissertação (Mestrado em Letras) - Universidade Católica de Pelotas, Pelotas, 2011.
RAE - Real Academia Española. Nueva Gramática de la lengua española - Fonética y Fonología. Barcelona: Espasa Libros, 2011.

TOMÁS, Tomás Navarro. Manual de pronunciación española. Madrid: Consejo Superior de Investigaciones Científicas. Ministerio de Educación y Ciencia, 2004.

ZIMMER, Márcia Cristina; ALVES, Ubiratã Kickhofel. A produção de aspectos fonético-fonológicos da segunda lingual: instrução explícita e conexionismo. Linguagem \& Ensino, v. 9, n. 2, p. 101-143, 2006.

ZIMMER, Márcia Cristina; ALVES, Ubiratã Kickhofel. Uma visão dinâmica da produção da fala em L2: o caso da Dessonorzação Terminal. Revista da Abralin, n. esp. 2, p. 221-272, 2012.

Recebido: 15 de agosto de 2013

Aprovado: 24 de outubro de 2013

Contato: juliana.feiden@fulbrightmail.org ukalves@gmail.com finger.ingrid@gmail.com 